Thorax, 1978, 33, 10-18

\title{
The thorax in history 1. From ancient times to Aristotle
}

\author{
R. K. FRENCH
}

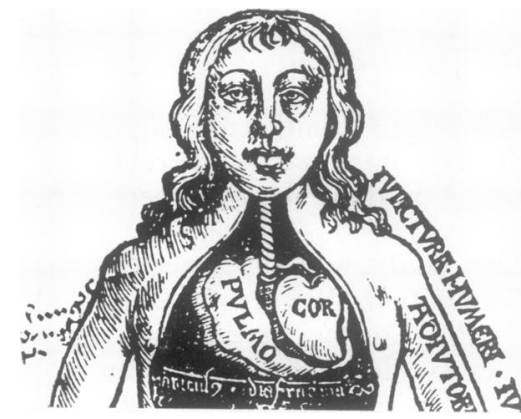

From the Wellcome Unit for the History of Medicine, University of Cambridge

\section{Introduction}

During most periods of human history dissection of the human body has been impossible, principally because of religious aversion to the perpetual disfigurement of the body in the afterlife. Yet man naturally had a great curiosity about the nature of his inside, and in the absence of direct observation he had to resort to a number of indirect methods. We can speak of the anatomical ideas generated in this way as 'knowledge' because they were held to relate to the real world, and they played the same part in the science of the time as anatomical ideas do now: they belong to the history of anatomy as much as morphological ideas judged on modern criteria.

We may list the indirect ways of learning about the internal structure of man as follows:

(1) analogy with animals;

(2) inferences from the externally visible structures of man;

(3) from natural philosophy as a whole; and

(4) from function.

We shall see each of these at work while man was attempting to discover the structure and function of his own thorax. In subsequent papers we shall see how ideas generated in these ways were transmitted to later generations and competed, up to at least the time of Harvey, with ideas about the thorax derived from observation. The problems that Harvey solved were Greek problems, not those of the seventeenth century alone.

Let us start with the last of our categories, how ideas about the thorax were generated from ideas about function. There are a number of what we might call fundamental physiological observations that primitive and archaic man made about the living body. The living body is warm, it breathes, and it moves with an innate motion and in reaction to external changes-four things it does not share with the dead body. The principle of life was therefore hot, mobile, associated with breath, and, it was widely thought, it preserved some kind of life of the individual after the death of the grosser physical body. It was natural to 0 think that this principle of life had some location in the living body, and many early natural philo- $\rightarrow$ sophers gave considerable thought to the problem $\stackrel{\mathbb{O}}{\circ}$ of which organ was the seat of the soul. The structural knowledge they employed in this matter rested on what we might call fundamental $\vec{\varphi}$ anatomical observations, which parallel the fundamental physiological observations just listed. These anatomical observations concern the first two of the categories listed at the beginning of this paper, that is to say, most primitive peoples have, and had, a knowledge of the internal organs roughly at the level of the butcher or cook who prepares $\varrho$ an animal for the table. The major organs were $\overrightarrow{\overrightarrow{0}}$ known, and there was a rough idea of their rela- 3 tions in the body. The smaller mammals are prepared for the table by the removal of the paunch and pluck: the abdominal viscera are first removed and then the heart and lungs are 음 removed together from the thorax. The disem- $x$ bowelled abdomen of mammals reveals two major $\frac{0}{3}$ vessels branching into the limbs posteriorly and disappearing through the diaphragm anteriorly. Observation of the external features of man re- $₹$

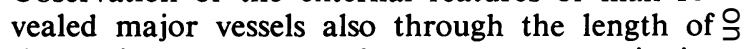
the neck. It was natural to assume a continuity of the two sets of vessels through the thorax, which was less open to direct observation, even in N animals, as it was defended by the ribs and its internal details were removed in the pluck. It 0 was clear that the heart was in some way con- $\underset{\omega}{ }$ nected to vessels, but it is characteristic of early physiological and anatomical speculation that thise connection was not elucidated until anatomy be- $\overparen{\varnothing}$ came a recognised discipline. Yet the heart had $\stackrel{\mathcal{P}}{+}$ what most of the early soul-searchers were looking 0 for. It was at the centre of the warm body and $\stackrel{\vec{D}}{D}$ was perhaps therefore the source of that heat; it $\stackrel{\mathbb{Q}}{\Phi}$ was mobile with an innate mobility discoverable $\stackrel{\mathbb{Q}}{\Omega}$ in the pulse, a mobility which increased with the motions of the body. The motion of the heart was 
also clear in anger and fear, and it clearly reacted in surprise to sudden external changes. It seemed to share most of these characteristics with the life principle, the attributes of which had been arrived at from the physiological observations above. Was not the heart the seat of the soul? Many societies have thought so. The Egyptians treated the heart with reverence during embalming, replacing it in the body cavity or preserving it separately in a jar. In contrast, the brain was considered worthless and was removed piecemeal through the nose with a hook. The heart and its associated vessels were central to the physiology of the living body in Egypt. The pulse was the heart 'speaking' through the vessels; the vessels carried from the heart the secretions and humours necessary to every part; the vessels were responsible for pathological conditions; and they carried the 'breath of life' and the 'breath of death'. The heart was also important in ancient Indian medicine, and the structures by which it communicated to the rest of the body, the vessels (blood vessels, nerves, 'sinews' in general, all regarded as similar and grouped under the same name), were in both cultures treated to a numerological symmetrisation in a scholastic manner. ${ }^{1}$

\section{PNEUMA, PSYCHE, AND THYMOS}

While the heart seemed to have most of the characteristics expected of a corporeal seat of the soul, it did not have all. The exception was that there was no obvious anatomical pathway for the soul-bearing breath to reach the heart. The search for such a pathway caused many of the difficulties of the later period when anatomy became a discipline, and it also opened the way for other traditional ideas on the soul and on the body to enter the physiological history of the thorax. We can see these ideas most clearly in early Greek thought. Firstly, there was the traditional notion of at least two distinct souls in the body. The Homeric warrior's individuality and personal immortality were ensured by his psyche, and his life-energy, heat, motion, and the more material aspects of life were the properties of a breathsoul, the thymos. The breath soul was part of the common life of the universe, breathed in at the first breath of the infant and expired at the last breath of the dying man, returning to the world soul. In later Greek thought the idea was taken up by the stoic philosophers, who held that pneuma was the life-stuff of man and the universe and that in its various forms it was responsible for most of the activity of the physical world.

In Homer the psyche resided in the head while the thymos was contained in the chest. This early distinction between the locations of the different souls was greatly elaborated by later Greek philosophers and formed a basis of physiological thought for the next two thousand years. The brain as a possible seat of the soul came to attention largely as a result of empirical observation of the results of wound damage. While the rational physicians of the settled civilisation of Egypt built up their scanty anatomical and physiological knowledge of the heart and vessels into an elaborate and scholastic scheme of bodily function, the surgeons' empirical observations, collected together for the professional purposes of prognosis and advice on whether or not to treat a certain kind of case, were not intended for systembuilding, and no extended scheme of the function of the brain and spinal cord was constructed. In a word, the central nervous system was not discovered, although the observations by the Egyptian surgeons on the results of damage to the brain and nerve cord are surprisingly acute. ${ }^{2}$ The experiences of the soldiers of the warring tribes of early Greece do not reflect, any more than do those of the surgeons of Egypt, the physiological system-building of the physicians of a settled civilisation. They were only too well aware of the results of damage to the brain, and it is probably from these experiences that the psyche was said to exist in the head, a blow to which could cause loss of consciousness while the coarser thymos continued to vivify the corporeal body. ${ }^{3}$

The other tradition that enters the story at this point is the relationship of the liver to blood. It was widely held that blood was manufactured in the liver, and its central place in physiological schemes was perhaps represented by the Babylonians' use of the liver in divination. The liver was also seen to be obviously connected to one of the fundamental pair of vessels to be seen in the eviscerated abdomen of animals. The other vessel of the pair was connected to the spleen, the homologue of the liver on the opposite side of the body. Now, the various views about the nature and functioning of the body that we meet in the early Greek schools of medicine are compromises embodying more or less of these traditional ideas. Those who were convinced that the brain was the seat of the vivifying soul and who thought that this soul was derived from the surrounding air (or world soul) by means of the breath naturally held that the breath was drawn into the brain through the nose. It followed that the influence of the soul, or the quality of the inspired air, was transmitted to the rest of the body by the vessels, and for this reason we find that some early accounts 
of the vessels make the fundamental pair, assumed to be continuous throughout the body, take their origin from the brain, with only minor connections or inosculations with the heart, liver, and spleen. In contrast, those who believed that the heart was the seat of the soul were obliged to postulate an anatomical pathway from the lungs to the heart. As we shall see, this was not difficult before the cardiac valves were discovered, but thereafter it caused a great deal of trouble. Secondly, they had to postulate that the vessels arose in the heart and carried the influence of the soul from it to the rest of the body. There are greater morphological grounds for this assumption than for the statement that they arise in the brain, but the anatomical battle fought for the hepatic, rather than cardiac origin of the veins was longer lasting. Notice that all these anatomical statements imply an understood sense of functional direction: there need be no morphological distinction between the statement that the vena cava 'arises' in the liver and the statement that it begins in the heart. The writer is thinking not in morphological terms, but in terms of the faculty which the veins were thought to possess and the direction of flow of the contained fluids. Thus those who held that the vessels arose in the brain described the coming together of many fine 'origins', in the manner of tributaries; this is morphologically identical to saying that the fundamental pair of vessels ramify into the head, as some of the 'cardiocentrists' believed. As in the case of the postulated pathways for respired air, in this case it is physiological considerations that determine the anatomical statements.

\section{The early Greek writers}

HEART OR HEAD?

The question whether the heart or the head was the dominant organ of the human body, the seat of the soul, was debated among the presocratic philosophers of Greece. It is sometimes said that Alcmaeon dissected out the eye and observed the optic chiasma and the connection of the optic nerve with the brain, but it seems probable that there is a confusion in an important passage of Chalcidius, ${ }^{4}$ and that these feats should instead be attributed to the later Herophilus (a fact which does not emerge from the usual sources). At all events, Alcmaeon had a theory of knowledge based on sensation, and he held that the seat of understanding was the brain.

The influence of Alcmaeon (and of Pythagoras) is said to have been strong in the medical school of Croton, and the belief that the brain was the centre of consciousness and the senses became $\stackrel{\vec{F}}{\stackrel{F}{?}}$ characteristic of that school. During the sixth cen-? tury BC other medical schools were also develop- $\frac{\bar{\sigma}}{\bar{C}}$ ing in Sicily, for example, and at Cnidos and Cos. ${ }^{5} \frac{\sigma}{\sigma}$ The influence of Empedocles was felt in the Sicilian school, and it was consequently main- ڤs tained by the Sicilians that the heart was the most $\vec{\circ}$ important organ in the body and respiration the most important function; they were 'cardiac pneu- $\vec{\omega}$ matists' in the sense we have discussed above. Empedocles had also said that the body contains $x$ fleshy tubes which contain blood and which open ${ }_{\omega}^{\omega}$ out at their fine distal terminations at the skin, drawing in and expelling air as the blood sank and $\vec{\circ}$ rose in the vessels. This notion became importanto when the later distinction between air and blood- carrying vessels (ie, arteries and veins) was made, T as we shall see. The importance of inspired air as음 a carrier of life is clear from this idea, which did not of course preclude air reaching the heart through the normal respiratory channels. As for $\vec{\bullet}$ the other medical schools, that of Cnidos reflected $\infty$ the teaching of the Egyptian physicians, and it is possible that the traditional attention paid to theo hcart and vessels in Egypt led here to a distinction between arteries and veins. The school of Cos was the traditional home of Hippocrates, and the $\frac{\varnothing}{\varnothing}$ anatomical ideas of the Hippocratic writings are $\varrho$ discussed below. Most of what we know about $\overrightarrow{\overrightarrow{0}}$ these early schools and persons is derived from 3 fragments, and we should be careful not to impute? too elaborate a physiological scheme to any of them. While we have some information as to their opinions of the most important organ of the body응 we are not so sure about their ideas on the loca- $x$ tion of the different souls, the psyche (or nous) and the thymos (or pneuma). For example, Philolaus in the fifth century, although influenced $\mathrm{O}$ by the Croton school and believing that the mind, nous, was in the brain, held also that the soul, $\frac{}{5}$ psyche, was in the heart. Philolaus also believed 7 that the umbilicus was a third organ of major importance in the body, responsible for growth. N In effect, Philolaus had distinguished between a rational, vital, and vegetative faculty, an idea that assumed major importance in biological historyw through its elaboration at the hands of Plato, Aristotle, and Galen. ${ }^{\circ}$

Many of these ideas are found in Plato, some of them from Philolaus through Plato's physician, Philistion. Plato's purpose in the Timaeus was not anatomical or physiological, and the only interest $\overrightarrow{\mathbb{D}}$ we have in the work in connection with the history $\frac{\mathbb{P}}{\mathbb{D}}$ of the thorax is that in it the fragmentary remarks 0 of the presocratics are extended. In the Timaeus we find suggestions of the fundamental pair of $\varnothing$ 
vessels, ramifying in the head; of important vascular connections of the heart; and of a strange network of pathways of air, fire, and perhaps blood, existing both inside and outside the thorax, which seems to owe something to the respiratory function of the Empedoclean fleshy tubes. Much more important in the Timaeus is Plato's description of the three souls of man, a hierarchy of bodily control that owes something to presocratic ideas we have now met and which Plato elaborated in a political form in the Republic. No doubt Plato's political ideas were the father of his biological: the highest soul of man, the rational, is located in the head, that part of the body nearest to the heavens whence the soul came, and its political counterpart in the constitution of a polis is the ruling class of philosopher princes, who alone have the wisdom to rule. The lowest soul is relegated to the liver, where its duties include nourishing the rest of the body and its weaknesses include the baser emotions and desires. Its political counterpart is the lowest social class of workers, whose products are useful to society but whose base instincts have to be controlled. Of direct concern to us is the soul that Plato describes between these two. The vigorous, fiery soul, located in the heart, with the courageous attributes of the warrior class, has its origins in the vaporous breath soul of the old tradition: Plato called it thymos. ${ }^{7}$

\section{EARLY ANATOMICAL DESCRIPTIONS}

One of the earliest accounts of the vessels ${ }^{8}$ that sets out to give an anatomical description of them is that of Syennesis of Cyprus, as reported by Aristotle. ${ }^{9}$ This account makes little anatomical sense if our criterion is modern morphology, but in the context of early Greek thought we can see at once its position in tradition. Thus there is a basic pair of veins, continuous from abdomen to thorax. The connection of each vein of the pair with the kidneys is noted, and that with the liver on one side and the spleen on the other. As in other traditional accounts, including Plato's, the vessels are said to cross from right to left and vice versa. The vessels are said to arise from the umbilicus (perhaps because of its fetal importance) and consequently they have but little connection with the heart, which is what we would expect in a non-cardiocentrist physiology. The most obvious of such physiologies was the cerebrocentrist, and an example is that of Diogenes of Apollonia. He was a pneumatist, believing that air was the fundamental substance of the universe, the intelligence of the macrocosm, and, when breathed into man, the giver of life and intelli- gence. Air first reached the brain and left its best parts there, bestowing sense perception and understanding, and then passed to the rest of the body in the vessels with the blood. The heart does not play a major role in the format of the vascular network, which is again in the form of a ramifying fundamental pair that is most obvious in the abdomen and which passes unchecked through the thorax, giving branches to the heart, up to the head. Again, the vessels on one side of the body are called hepatic and those on the other splenic, either because of their attachments to the liver and spleen or because these organs served to give their name to the right- and left-hand side of the body.

Much of what is common to the authors mentioned by Aristotle appears also in the works of the Hippocratic corpus. The cerebrocentrist The Sacred Disease ${ }^{10}$ describes a fundamental pair of vessels coming to the brain from the liver and spleen, and it gives an account of the downward extension of these vessels past the kidneys and into the limbs. Branches are given off in the thorax to the heart, and in general there is a marked similarity to the description given by Diogenes, down to the details of the superficial position of the vessels in the neck. A more extended account of the vessels was given by Polybus, said to have been Hippocrates' son-inlaw and said by Galen to have taught the genuine opinions of Hippocrates. According to Polybus, there were four pairs of vessels, all descending from the head, two pairs of which descended throughout the body, lying on either side of the backbone as in other accounts, and the remaining two pairs of which served the lungs, the kidneys, and the spleen and liver on either side. Apart from this doubling-up of numbers, this account is in close agreement with the traditional schema. In addition to this, the Hippocratic On the Nature of the Bones ${ }^{11}$ gives an account of the vessels that is similar to but not identical with the one attributed by Aristotle to Syennesis, and Aristotle's version of Polybus' account turns up again in the Hippocratic works On the Nature of $\mathrm{Man}^{12}$ and On the Nature of the Bones. The Hippocratic Epidemics 11 contains an account close to that of Diogenes.

There is evidence that these Hippocratic and Aristotelian versions do not depend on each other but represent some common source. Their independent appearance in different bodies of writing argues that they represent an important scheme of vascular organisation in the pre-Alexandrian period; in all cases there is a fundamental pair of vessels running the length of the body on either 
side of the spine, giving off branches to important organs. In all cases the heart is not of central importance; Syennesis, Polybus, and, in effect, Plato giving it no communication to the system, only Diogenes and the author of The Sacred Disease granting it branches from the fundamental pair. In all accounts except The Sacred Disease the vessels are said to cross at some point from one side of the body to the other. In all accounts except Plato's the important organs served are the liver and spleen, the kidneys, and the genitalia. What all the accounts have in common is that they are not cardiocentric, and there is distinct evidence that some at least represent pneumatic cerebrocentrist opinion. That they agree in this particular is due partly to the fact that Aristotle selected these opinions for refutation, since they all disagreed with his own cardiocentric view.

To summarise the position we have now arrived at, we find that there was considered to be a fundamental pair of vessels in the body, the vena cava and aorta of modern terminology, which, observed in the gutted abdomen of animals in close relation to the kidneys, spleen, and liver, were thought to extend as continuous vessels to the brain. Some connection was admitted to the heart, and some account was taken of traditional views that gave the heart a sensory function. The whole system was symmetrical, containing uniformly blood alone or with spirit derived from the inspired air. The fundamental pair of vessels was the product of analogy with animals and observation of the external features of man; the functional direction and pathways of these vessels and their branches in the body were determined by considerations derived from natural philosophy as a whole, that is, the life-giving macrocosmic pneuma and its entry into the body.

\section{ARTERIES AND VEINS}

This picture was radically altered by two discoveries: the first was gradual recognition of the distinction between arteries and veins, and the second was the discovery of the cardiac valves. The second discovery was not made until anatomy had become a discipline in its own right, and the story of its effect on these traditional ideas will be discussed in the next paper. The distinction between arteries and veins seems to have been made on two grounds. Firstly, it was noticed that some blood vessels, phlebes, had thicker coats of a rougher texture than others. Secondly, it was found in the dead animal that some vessels contained not blood, but air. No doubt animals were killed by having their throats cut, or at least the blood was drained off before butchering, and the arteries, but not the veins, would be found empty. It is sometimes said ${ }^{13}$ that Alcmaeon found that some phlebes contained air. It is also said $^{14}$ that Euryphon, a Cnidian contemporary of Hippocrates, distinguished between arteries and veins, noting, however, that both contain blood. He presumably made the distinction by reason of the speed by which blood is emitted when arteries and veins are cut in the living animal, or from the different structure of the venous and arterial coats. Now, the discovery that some vessels in the dead animal appear to have carried air in life was particularly acceptable to the pneumatists, and the notion of air- or spirit-filled arteries developed a strong tradition of its own, as we shall see. Phlebes remained in use for 'vein', while arteria came to be used as 'air-carrying vessel'. As such it included the trachea, which was subsequently known until the seventeenth century as the arteria aspera, 'harsh' from its cartilaginous texture; arteria was part of the respiratory system, whether the part from the mouth to the lungs, from the lungs to the heart, or from the heart to the body. Secondly, the distinction between arteries and veins meant that the fundamental pair of vessels of the abdomen was no longer a symmetrical pair, for one was an artery and one a vein. Henceforth the terms 'hepatic' and 'splenic' came to indicate 'vein' and 'artery', or, more precisely, vena cava and aorta, and not merely the visceral relations of the vessels or their right- or left-hand location. Yet the different structure of these two vessels implied a different function. The hepatic vessel was after all clearly connected to the liver, which was often thought of as the source of blood, and it was widely agreed that this vessel was indeed full of blood, the food of the body. Did it not have a nutritive function? Did not then the artery have a respiratory, spirit-carrying function?

THE WRITING OF ARISTOTLE While many agreed that the vessels did have $N^{\circ}$ these functions, Aristotle did not. He did not in- N deed believe that pneuma was breathed into the $N$ body; the breath was simply air, to cool the innate $\omega$ heat of the heart. Pneuma, like this heat, was innate, and it acted as a bodily agent of the soul.

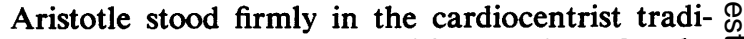
tion, and in his biological writings we have for the ? first time an extended account of researches under- $\frac{0}{0}$ taken for reasons of intellectual enquiry and $\vec{D}$ teaching. Unable to dissect the human body, he $\stackrel{?}{\stackrel{\odot}{\mathbb{P}}}$ examined the validity of the indirect ways of gain- $\propto$ ing anatomical information mentioned at the beginning of this paper. His extensive researches 
in the structure and function of animals ${ }^{15}$ were designed to supply the causes and principles that lay behind the appearances. His theory of knowledge claimed that true knowledge was knowledge of the fourfold causality of every natural change, the most important of which was final causality, revealing the purpose that lay behind the process of change. Other writers, like Galen ${ }^{16}$ and the author of the Hippocratic De Corde, ${ }^{17}$ took this purpose to be the rational plan of a personalised and craftsmanlike Nature or Creator, and anatomical and physiological work then became an exercise in revealing the skill and wisdom with which the body had been put together. The body was in this way worthy of attention for its own sake, not merely as a means of achieving medical purposes, and anatomy became a discipline, with its own methods of procedure, and formalised within a framework of teaching. We see in Aristotle, who stands at the beginning of this tradition, a justification of the empirical method of observation, ${ }^{18}$ novel among the Greeks. But we also see the force of traditional ideas, and this seems to be the basic reason why Aristotle claimed the heart as the primary organ of the body. It was central, mobile, and hot, and well supplied with structures which served to communicate between it and the rest of the body in a sensory and motor capacity. As a single, central organ it was the most suitable as the centre of physiological processes, the seat of the soul. The soul had nutritive, generative, sensory, and motor faculties in a hierarchy like that hinted at by Philolaus and set out by Plato. Despite the suggestions in the accounts of his predecessors about the connections between the sense organs and the brain, Aristotle and his generation remained in ignorance of the central nervous system, a fact which contributed to his placing the soul in the heart. It is sometimes said that Aristotle claimed that the heart was the origin of the nerves, but this rests on a misunderstanding. Blood vessels, he said, may at their finest branches become too narrow to contain blood; both kinds of vessel were called poroi, a word already in use for the connections (which he did not consider sensitive) between the eye and the brain, and Aristotle may have been thinking of what we know to be nerves. On the other hand, he used the term neura, which has survived in technical literature to mean 'nerve', to cover all fibrous structures, tendons, ligaments, and perhaps nerves as well. It was a traditional Greek idea that the movement of the limbs was caused by the fibrous structures at the joints, not by the muscles, which they called 'flesh' and regarded as a padding for the bones. Aristotle thought indeed that the heart was the origin of these fibres, and as their root and source he pointed to fibrous structures associated with the cardiac valves (which he did not recognise as such). There was, however, no physical continuity between these cardiac neura and the fibres of the joints, and Aristotle did not think of them as sensitive 'nerves'.

\section{ARISTOTLE ON THE HEART}

As for Aristotle's anatomical description of the heart and its vessels, there are two major difficulties. The first is his statement that large warmblooded animals have three cavities in the heart, the smallest have only on $\mathrm{e}^{19}$, and those animals of middle size have two cavities. With Nehemiah Grew 'One would a little wonder, how so observing a man, should discover so many mistakes, in so few words'. ${ }^{20}$ There is little evidence of a traditional or mystical view that may have influenced Aristotle, as Thompson suggests. ${ }^{21}$ There is, similarly, little basis anatomically for Aristotle's opinion, although various attempts have been made by such figures as Galen, Vesalius, Huxley, and later scholars to explain it on the basis of Aristotle's misinterpretation rather than his error. Galen suggested that the 'middle cavity' of the heart, as described by Aristotle, was a portion of the right ventricle, and Thompson is inclined to agree. ${ }^{22}$ Ogle thinks that the middle cavity was the left ventricle, the smallest the left auricle, and the largest the right ventricle. ${ }^{23}$

The latter explanation depends upon the nature of the cavities and the vessels with which Aristotle said they communicate. Broadly, this is the second of the difficulties we meet in Aristotle's account of the vascular system. As noted above, the intercommunication of the heart, lungs, and large blood vessels is fundamental to the understanding of the body machinery, and problems associated with it were vigorously debated from before Aristotle to the time of Harvey. Aristotle said that the right cavity of the heart contains the most abundant and the hottest blood, and the left, the least and the coldest. The relative abundance of blood in the differcnt cavities may perhaps be explained by Aristotle's method of killing his animals before dissection. This was strangulation, which would leave the veins and the right side of the heart full of dark blood and the left almost empty. ${ }^{24}$ This method has been called a genuine advance over the more common technique of cutting the throat of the animal, thereby draining off a portion of the blood. ${ }^{25}$ Aristotle said the middle cavity contained a medium quantity of blood, which was the purest and thinnest in the body. ${ }^{26}$ 
This cavity serves as a common centre for the other two. To it are connected the air-filled aorta and arteries, while the 'great vessel', the vena cava, is connected to the largest cavity. Here we have a clue as to the origin of Aristotle's idea that the heart has only three cavities. The junction of the superior and inferior venae cavae with the heart is such that the vena cava appears to be a relatively straight vessel running the length of the body and inosculating with the heart at one part of its circumference. This is more marked in the bodies of apes and young children, which we may suppose were more familiar to Aristotle and his predecessors than the adult human body. This apparent continuity of the vessel is doubtless the reason it was supposed even before Aristotle to run the length of the body, beginning perhaps in the head and merely communicating with the heart on its journey; in other words, one of the traditional fundamental pair of vessels of the body. For Aristotle the right auricle was simply the dilated junction of this vessel with the heart (much as Galen thought of both auricles as merely expanded portions of the veins rather than as chambers of the heart), and he consciously identifies this apparently single vena cava with the fundamental vessel of the traditional pair mentioned by Homer.

Thus the largest cavity of the heart described by Aristotle is identified with the right ventricle by its attachment to the vena cava, and, correspondingly, the middle cavity can be said to be the left ventricle as Aristotle says it communicates with the aorta. All three cavities are said to have channels to the lungs, but two of these are too small to be seen clearly, and we are left to infer that as the obvious channel is that from the largest cavity, ${ }^{27}$ it must be the pulmonary artery. Its branches in the lung do not communicate with the branches of the windpipe but nevertheless receive air from them and pass it back to the heart, to both right and left cavities. Aristotle does not make it clear whether the air returns to the right ventricle by means of the vessel already mentioned, and in other places he says that the lungs are supplied with branches of 'the great vessel'. There is also a confused passage which seems to give the aorta as well as the vena cava some connection with the lungs. It has been suggested that such a connection may refer to the fetal ductus arteriosus, a suggestion that may be significant taken in conjunction with the opinion that Aristotle's direct knowledge of the human body was limited to fetal material. ${ }^{28}$ There is much that is obscure in Aristotle's account, and strong evidence of textual corruption does not help one to understand his thought. ${ }^{29}$ However, not all is confusion. The heart is the source of heat, and its left side is more associated with air than with blood. The contents of the left side are purer, and if we include the central cavity with the left, it is the source of the aorta and hence all the arteries. All these details are shared by the Hippocratic On the Heart (De Corde). Moreover, we can gather from Aristotle that the lungs were nourished by blood either from the right side of the heart or direct from the vena cava, and if the former was the case, there must have been a twoway flow of blood and air in the vessel from the right ventricle to the lung. The importance of this in view of later ideas will be mentioned in discussing On the Heart. On one important point Aristotle differs from the Hippocratic text: he makes no mention of valves in the heart.

Aristotle's lack of precision in describing the connections of the right ventricle with the lung has caused considerable trouble to later commentators. Ogle suggests that the pulmonary artery was taken by Aristotle to be part of the vena cava, separated from it by the right ventricle but shown to be allied by its connection to this same cavity, and also by the fact that both vessels are filled with dark blood after death and that both have similar thin walls. His argument is then that Aristotle referred to both vena cava and pulmonary artery under the collective title 'great vessel' and the systemic arteries and pulmonary vein as 'aorta' collectively. However, as D'Arcy Thompson points out, to admit this would be to lose the force of Aristotle's well-marked distinction between the sinewy texture of arteries and the membranous nature of veins. Thompson thinks that Aristotle groups the pulmonary artery and aorta as 'aorta' and the vena cava and pulmonary vein as 'great vessel' despite, as Thompson admits, their disparate origins from opposite sides of the heart. It is notable, however, that in De Somno et Vigilia (458a) Aristotle specifically speaks of the two vessels, aorta and vena cava; he is not including the pulmonary vessels under a collective name. If we accept this, and other criticisms of Ogle's explanation, we still have to admit that Aristotle did not adequately describe the pulmonary artery. One reason for this, that there was simply no traditional knowledge for Aristotle to draw on, has perhaps been overlooked. Even if we assume that this was an area where he might be expected to employ animal dissection to best advantage, it is now clear from what has been said that much of his account depends on inherited information. It has also been seen that the two fundamental vessels of the traditional accounts had surprisingly 
little connection with the heart, and even less with the lungs, so that Aristotle had little to build on in attempting an anatomy of these two organs and their vessels. Another example of Aristotle's dependence on inherited information is his description of a vein from the liver to the right arm, which is bled by surgeons to relieve pain from the liver. Lloyd ${ }^{30}$ calls this 'superstitious' but it is, of course, a survival of the traditional accounts such as those of Diogenes and of The Sacred Disease. ${ }^{31}$

So Aristotle had no reason to know of the vascular connections of the heart and lungs. Probably from his own observations he attempted to gather enough anatomical information to supply his physiology with a means to provide air for the heart and blood to nourish the lungs. The result is similar to other schemes no doubt owing something to his, that of On the Heart and that developed by Galen. Had Aristotle noticed and understood the valves, as these two later authorities did, he would have been obliged to describe the anatomy of the vessels in greater detail. As for the rest of the vascular system, Aristotle describes well enough the inferior vena cava and the aorta, as they are described in the more advanced of the traditional sources. In rejecting other details from these sources, he mentions that one method employed by the old anatomists was to observe the bodies of living men 'reduced to extreme attenuation', ${ }^{32}$ a method which resulted in too great an emphasis being put on the superficial vessels. This may explain the similarity of the descriptions of the superficial veins of the neck given in The Sacred Disease and by Diogenes. Aristotle also describes the jugular veins and notes the stupefying effect of compressing them in a living man. He recalls the veins of the neck described by Homer.

There are several remaining points to be noted. In describing the two halves of the heart as separate systems, each with its own blood, ${ }^{33}$ Aristotle provided a basis on which Galen's ideas could be built. This has been said ${ }^{34}$ to be his greatest advance over earlier accounts. Among the reasons that Aristotle put forward for locating the origin of the veins in the heart rather than the liver was that the heart was single, as befits the source of a single system. The liver, on the other hand, appeared to have a substantial vein running through it (no doubt the vena porta and vena cava regarded as a single vessel) and so could not be the origin of the veins. The emphasis on the singleness of the heart almost implies that the liver is double: 'For the liver and spleen would seem to lie half way between the single and double organs. For they may be regarded either as con- stituting each a single organ, or as a pair of organs resembling each other in character'. As Ogle says, ${ }^{35}$ it was a common ancient opinion that the spleen was the left homologue of the liver, and we can see that this is the most convincing of a series of hints as to why the two fundamental vessels of tradition were the 'hepatic' and 'splenic'. Clearly, some physiological scheme, dominated by a regard for symmetry, took the liver as the dominant organ of the right side of the body, giving its name to the vessels on that side.

\section{Notes and references}

1 On Egyptian medicine in general see Wilson, J. A., 'Medicine in ancient Egypt', Bulletin of the History of Medicine, 36, (1962) 114-123; Ghalioungui, P., Magic and Medical Science in Ancient Egypt, London, 1963, and Dawson, W. R., 'Egypt's place in medical history', in Science, Medicine and History, edited by E. A. Underwood, Oxford, 1953. For medical texts, see Ebbell, B., The Papyrus Ebers, Copenhagen and London, 1937. On Indian medicine see Filliozat, J. La Doctrine Classique de la Médecine Indienne, Paris, 1949.

2 See Ranke, H., 'Medicine and surgery in ancient Egypt'. Bulletin of the History of Medicine, 1, (1933) 237-257. The only surviving surgical text has been published by Breasted, J. H., The Edwin Smith Surgical Papyrus, 2 volumes, Chicago, 1931.

3 Altschule, M. D. 'The pneuma concept of soul', J. Hist. Behav. Sci., 1, (1965) 315.

4 The whole question of dissection at Alcmaeon's time is discussed by Lloyd, G. E. R., 'Alcmaeon and the early history of dissection', Sudhoffs Archiv., 59 (2), (1975) 113-147.

5 Wellmann lists 10 early Greek medical schools, distinguishing them primarily on their approach to the question of the most important organ of the body. Wellmann, M., 'Alkmaion von Kroton', Archeion, 11, (1929) 156-169.

6 On Philolaus, see Diels-Kranz, Die Fragmente der Vorsokratiker, Berlin, 1964. See, however, Kirk, G. S. and Raven, J. E., The Presocratic Philosophers, a convenient source for the presocratics, and which sums up the evidence against the authenticity of the fragments of Philolaus.

7 The Timaeus is available in a number of editions and translations. Two useful companions to the work are Taylor, A. E., A Commentary on Plato's Timaeus, Oxford, 1928 and Cornford, F., Plato's Cosmology, London, 1937.

8 An essential source on the entire question of the heart and vessels in Greek writers in Harris, C. R. S., The Heart and Vascular System in Ancient Greek Medicine, Oxford, 1973.

9 Historia Animalium 511b.

10 Adams, F. (trans.) The Genuine Works of Hippocrates, vol. 2, London, 1849. 
11 Littré, E. (trans.) Oeuvres Complètes d'Hippocrate, vol. 1. Paris, 1839.

12 Chadwick, K. J., and Mann, W. (trans.) The Medical Works of Hippocrates, Oxford, 1950.

13 Castiglioni, A., A History of Medicine, 1947, p. 136.

14 Neuberger, M., History of Medicine (trans. Playfair, E.) vol. 1, p. 116, London, 1910.

15 The Historia Animalium was designed to give an account of the characteristics of animals, and $D e$ Partibus Animalium conducts an investigation into the causes of these features. What Aristotle has to say on the soul is found largely in De Anima. Aristotle's works are conveniently consulted in the English translation of the Oxford edition.

16 In particular in his De Usu Partium: see the English translation by May, E. T., Galen on the Usefulness of the Parts of the Body, Cornell University Press, 1968.

17 This has been translated by Hurlbutt, F. R., 'peri Kardies', Bull. Hist. Med., 7, (1939) 1104-1113.

18 See Lloyd, G. E. R., Aristotle, Cambridge, 1968.

19 Historia Animalium 496a, 513a. De Partibus Animalium 666b.

20 Quoted from Cole (1949) p. 39.

21 Historia Animalium 496a 20 note 4.

22 Historia Animalium 513a.

23 In De Somno et Vigilia 458a, the aorta is said to be connected not to the middle cavity but to one of the side ventricles.

24 De Partibus Animalium 667a.
25 Wilson, L., 'Erasistratus, Galen and the "pneuma" ', B.H.M. 33 (1959) 293-314.

26 See also Historia Animalium 496b.

27 Aristotle says 'even the two small [cavities]' have channels to the lungs. Historia Animalium 496a.

28 Platt, who makes the suggestion, extensively re- is stores the Greek to get an answer to the problem. Platt, A., 'Aristotle on the heart', in Studies in $\vec{\circ}$ the History and Method of Science, edited by C. Singer, vol. 2, Oxford, 1921.

29 The anastomosis between the vena cava and aorta apparently described by Aristotle is not dealt with here as it seems clear it is a textual corruption. The reader is referred to the notes by Ogle and Thompson for further details of the various attempts to interpret Aristotle's statements on the heart and vessels.

30 Lloyd (1968) p. 74

31 There is a possibility that the vena azygos may have been represented in the traditional accounts and Thompson thinks that the vein here described by Aristotle may be based on an imperfect knowledge of it.

32 Historia Animalium 511a.

33 De Partibus Animalium 666b.

34 Harris (1973).

35 De Partibus Animalium 669b 15 note 2.

Requests for reprints to: R. K. French, PhD, Director, Wellcome Unit for the History of Medicine, University of Cambridge, Free School Lane, Cambridge. 